ORNL/MD/LTR-75 Level 2

OAK RIDGE NATIONAL. LABORATORY

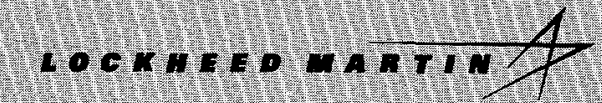

\title{
Technical Specification: Mixed-Oxide Pellets for the Light-Water Reactor Irradiation Demonstration Test
}

\author{
B. S. Cowell
}

Fissile Materials Disposition Program

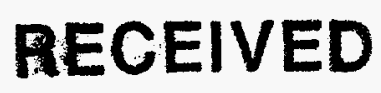

\author{
JUL $18 \mathrm{mP7}$ \\ OSTI
}

MASTER,

LOCKHEED MARTN ENERGY RESEARCH CORPORATION FOA THE UNTED STATES

DEPARTMENT OF ENERGY

DISTRIBUTION OF THIS DOCUMENT IS UNLMATED 
This report was prepared as an account of work sponsored by an agency of the United States Government. Neither the United States Government nor any agency thereof, nor any of their employees, makes any warranty, express or implied, or assumes any legal liability or responsibility for any third party's use, or the result of such use, of any information, apparatus, product or process disclosed in this report, or represents that its use by such third party would not infringe privately owned rights. 


\section{DISCLAIMER}

Portions of this document may be illegible electronic image products. Images are produced from the best available original document. 
OAK RIDGE NATIONAL LABORATORY

MANAGED BY LOCKHEED MARTIN ENERGY RESEARCH CORPORATION

PHONE:

FAX

(423) $574-0656$

FOR THE U.S. DEPARTMENT OF ENERGY

INTERNET: ut1@Oml.gov

POST OFFICE BOX 2009

OAK RIDGE, TN $37831-8057$

Distribution

Technical Specification: Mixed-Oxide Pellets for the Light-Water Reactor Irradiation Demonstration Test

The enclosed document specifies the requirements for the mixed-oxide fuel pellets to be fabricated for the initial Advanced Test Reactor irradiation test sponsored by the Fissile Materials Disposition Program. The pellets will be fabricated by Los Alamos National Laboratory.

This is a Level-2 document as defined in the Fissile Materials Disposition Program Light-Water Reactor Mixed-Oxide Fuel Irradiation Test Project Plan, ORNL/MD/LTR-78.

Sincerely,

Brian S. Cowell

Fissile Materials Disposition Program

Enclosure: As stated above

Distribution: See enclosure 
ORNL/MD/LTR-75

Level 2

\section{Technical Specification: Mixed-Oxide Pellets for the Light-Water Reactor Irradiation Demonstration Test}

Revision 0 June 1997

B. S. Cowell

Oak Ridge National Laboratory

$\begin{array}{lll}\text { Concurred by: } & \begin{array}{l}\text { Stephen A. Hodge } \\ \text { (ORNL) }\end{array} & \text { June 12, } 1997 \\ \text { Concurred by: } & \begin{array}{l}\text { Kenneth M. Chidester } \\ \text { (LANL) }\end{array} & \text { June 18, } 1997\end{array}$

Prepared by the OAK RIDGE NATIONAL LABORATORY

Oak Ridge, Tennessee 37831 managed by

LOCKHEED MARTIN ENERGY RESEARCH CORP.

for the

U.S. DEPARTMENT OF ENERGY

under contract DE-AC05-96OR22464 


\section{Revision History}

\begin{tabular}{|c|c|c|}
\hline Revision number & Date issued & Reason for revision \\
\hline 0 & June 1997 & \\
\hline
\end{tabular}




\section{CONTENTS}

ABSTRACT.

1. SCOPE

2. APPLICABLE DOCUMENTS .

3. DEFINITION OF TERMS.

4. REQUIREMENTS

4.1 SAFETY REGULATIONS

4.2 MANUFACTURING PROCESSES

4.3 CHEMICAL COMPOSITION

4.3.1 Specified Composition.

4.3.2 Impurity Content.

4.3.3 Hydrogen Content

4.3.4 Oxygen Content

4.3.5 Fissile Component.

4.3.6 Chemical Analysis

4.4 ISOTOPIC COMPOSITIONS

4.4.1 Material Contents

4.4.2 Isotopic Analysis.

4.5 GRINDING.

4.6 WORKMANSHIP

4.7 DIMENSIONS AND FINISH .

4.7.1 Chipping of the Dished and Flat End

4.7.2 Chipping of the Circumferential Surface

4.7.3 Pits

4.7.4 Inclusions in Pellet Surface.

4.7.5 Cracks in Pellet Surfaces.

4.7.6 End-Capping and End-Flaking

4.7.7 Noncleanup.

4.7.8 Grinding Marks...

4.8 DENSITY

4.9 PELLET DIMENSIONS..

4.10 MICROSTRUCTURE

4.10.1 Grain Structure

4.10.2 Homogeneity.

5. QUALITY ASSURANCE REQUIREMENTS...

5.1 GENERAL.

5.2 ACCESS

5.3 ISOTOPIC COMPOSITION

5.4 NUMBER OF TESTS.

5.5 RETESTING

5.6 SIGNIFICANCE OF NUMERICAL VALUES ............................................................

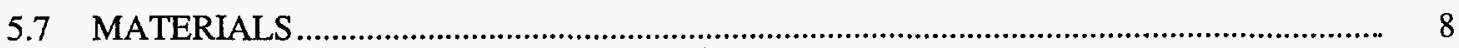

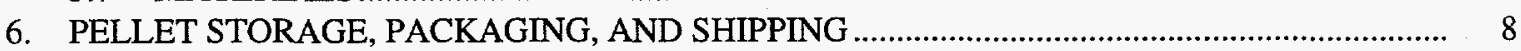

REFERENCES

APPENDIX A: EVALUATION OF MICROSTRUCTURE 


\title{
Technical Specification: Mixed-Oxide Pellets for the Light-Water Reactor Irradiation Demonstration Test
}

\author{
B. S. Cowell
}

\begin{abstract}
This technical specification is a Level 2 Document as defined in the Fissile Materials Disposition Program Light-Water Reactor Mixed-Oxide Fuel Irradiation Test Project Plan. It is patterned after the pellet specification that was prepared by Atomic Energy of Canada, Limited, for use by Los Alamos National Laboratory in fabrication of the test fuel for the Parallex Project, adjusted as necessary to reflect the differences between the Canadian uranium-deuterium reactor and light-water reactor fuels. This specification and the associated engineering drawing are to be utilized only for preparation of test fuel as outlined in the accompanying Request for Quotation and for additional testing as directed by Oak Ridge National Laboratory or the Department of Energy.
\end{abstract}

\section{SCOPE}

This specification covers the requirements for high-density sintered mixed-oxide (MOX) pellets, based on uranium with additions of plutonium, for partial length fuel elements that represent generic lightwater reactor (LWR) fuel for irradiation testing in the Fissile Materials Disposition Program Light-Water Reactor Mixed-Oxide Fuel Irradiation Test Project. ${ }^{1}$ Oak Ridge National Laboratory (ORNL) is leading the experiment design for the Department of Energy (DOE). Los Alamos National Laboratory (LANL) is fabricating the test fuel in the TA-55 fuel development laboratory. The test fuel will be irradiated in the Advanced Test Reactor at Idaho National Engineering and Environmental Laboratory (INEEL). This fuel pellet specification may be utilized for applications requiring test fuel pellets including experiments, demonstrations, and physics tests as approved by ORNL or DOE.

For the purposes of this pellet specification, ORNL will be considered the purchaser, and LANL will be considered the supplier. In all cases of MOX pellet manufacture using this specification, the quality assurance (QA) requirements and other requirements of this specification must be applied. Additional QA requirements are to be specified in the Fabrication, Inspection, and Test Plan (FITP) to be produced by LANL and accepted by ORNL. Any modifications to the requirements must be specified in the purchasing documents and agreed to by the supplier and purchaser. In cases of conflict, the provisions of this specification shall take precedence.

Users of this specification should note also that some requirements are in a developmental stage and may be amended (by appropriate revisions to this document) based on experience and/or manufacturer's capability.

\section{APPLICABLE DOCUMENTS}

The following documents, in effect on the date of the order for this fuel, shall form a part of this specification.

1. American Society for Testing and Materials (ASTM) Standards

- C753 Standard Specification for Nuclear-Grade, Sinterable Uranium Dioxide Powder

- C757 Standard Specification for Nuclear-Grade Plutonium Dioxide Powder, Sinterable 
- E11 Wire Cloth Sieves for Testing Purposes

- E29 Standard Recommended Practice for Indicating Which Places of Figures Are To Be Considered Significant in Specified Limits

- E112 Methods for Determining Average Grain Size

2. Quality Standards

10 CFR 830.120 Quality Assurance Requirements

3. Appropriate Jurisdictional Regulations and Standards

In the event of conflict, the following shall govern in order of precedence:

- appropriate jurisdictional regulations and standards and

- this specification.

\section{DEFINITION OF TERMS}

The following definitions are used in this specification.

1. Lot (powder lot). A lot is defined as a quantity of MOX powder-processed at one time-that is uniform in isotopic, chemical, and physical characteristics.

2. Primary blend. A primary blend is defined as a single lot of MOX powder containing $230 \%$ plutonium that is to be subsequently diluted with additional uranium to the final plutonium concentration specified in the purchase order.

3. Secondary blend. A secondary blend is defined as a single lot of MOX powder formed from dilution of a primary blend with additional depleted urania to the plutonium concentration specified in the purchase order.

4. Batch (pellet batch or sintering batch). A batch is a quantity of pellets made by the same process in one sintering run or one production run from a single lot of $\mathrm{UO}_{2}$ or $\mathrm{PuO}_{2}$ as identified by the suppliers. All pellets within a pellet batch shall be made from a single powder lot.

5. Crack. A crack is a bidimensional discontinuity caused by loss of cohesion in material under the influence of a stress.

6. End-capping and end-flaking. End-capping and end-flaking refer to imperfections localized at the edge of the pellet and connected with a conical bidimensional discontinuity above the pellet face. This type of discontinuity results from loss or weakening of the bond between particles under stress at the end of pressing.

7. Pit. A pit is a discontinuity (cavity, pore) in the surface of the pellet.

8. Chip (chipping). A chip is a discontinuity on the surface of the pellet due to breaking of the pellet material under mechanical forces.

9. Inclusion. An inclusion is foreign material embedded in the pellet matrix that is heterogeneous with the rest of the pellet.

\section{REQUIREMENTS}

\subsection{SAFETY REGULATIONS}

The supplier shall comply with all regulations of the applicable regulatory bodies governing criticality, health, safety, and the environment associated with the processing, testing, storing, and shipping of materials and pellets. No other requirement of this specification shall override these regulations. 


\subsection{MANUFACTURING PROCESSES}

Manufacturing processes, process qualification, and process controls shall be described in procedures and sequences in the FITP. The FITP shall be submitted to ORNL for review and acceptance prior to the start of operation.

\subsection{CHEMICAL COMPOSITION}

\subsubsection{Specified Composition}

The finished pellets shall meet the chemical composition as detailed in the purchase order or other documents. This shall be demonstrated by analysis of representative samples taken from each pellet lot. All weapons-grade (WG) plutonium fuel shall be delivered with a nominal total plutonium content in a sintered pellet of $5.00 \pm 0.05 \mathrm{wt} \%$ heavy metal unless otherwise specified in the purchase order.

\subsubsection{Impurity Content}

Finished pellets shall meet the impurity levels given in Table 1. The equivalent boron content (EBC), excluding the contribution of any intentionally added absorber, shall not exceed 4.0 using the EBC values given in Table 1. In the event of noncompliance, the supplier shall submit to the purchaser the results for review and mutual acceptance.

\subsubsection{Hydrogen Content}

The hydrogen content of finished pellets shall not exceed $1 \mu \mathrm{g} / \mathrm{g}$. The test procedure shall be accepted by the purchaser through the FITP acceptance process.

\subsubsection{Oxygen Content}

The MOX pellets shall contain oxygen equivalent to the metal-oxide mixture within the limits of $\mathrm{MO}_{1.995}$ to $\mathrm{MO}_{2.010}$, including analytical error where $\mathrm{M}$ represents the sum of the uranium and plutonium.

\subsubsection{Fissile Component}

The uncertainty in the reported fissile content of any given pellet shall be no greater than $\pm 0.01 \mathrm{wt} \%$ heavy metal of the nominal composition as specified in the purchase documents.

\subsubsection{Chemical Analysis}

The supplier shall certify the chemical composition of the finished pellets. This shall be done by analysis of the composition of finished pellets by the supplier or use of the certified powder analyses available.

\subsection{ISOTOPIC COMPOSITIONS}

\subsubsection{Material Contents}

The isotopic composition of the uranium and plutonium in the pellets shall be as stated in the purchase order or equivalent documentation. The WG plutonium shall have a ${ }^{239} \mathrm{Pu}$ content of $93.4 \pm 0.1 \mathrm{wt} \%$ heavy metal unless otherwise agreed between the purchaser and supplier. The depleted uranium shall have a $235 \mathrm{U}$ content of $0.26 \pm 0.05$ wt $\%$ heavy metal unless otherwise agreed between the purchaser and supplier. 
Table 1. Impurity limits in sintered fuel pellets

\begin{tabular}{lcc}
\hline Element & $\begin{array}{c}\text { Impurity limit } \\
\text { (ppm) }\end{array}$ & EBC factor \\
\hline Aluminum & 100 & 0.0001 \\
Boron & 1.0 & 1.0000 \\
Cadmium & 1.0 & 0.3172 \\
Calcium & 250 & 0.0002 \\
Carbon & 250 & 0.0001 \\
Chlorine & 50 & 0.0134 \\
Cobalt & 250 & 0.0089 \\
Dysprosium & 1.0 & 0.0818 \\
Europium & 1.0 & 0.4250 \\
Fluorine & 50 & 0.0001 \\
Gadolinium & 1.0 & 4.3991 \\
Gallium & As fabricated & 0.0001 \\
Hafnium & 1.0 & 0.0082 \\
Indium & 10 & 0.0001 \\
Iron & 500 & 0.0006 \\
Lead & 400 & 0.0001 \\
Magnesium & 200 & 0.0001 \\
Manganese & 250 & 0.0034 \\
Molybdenum & 250 & 0.0004 \\
Nickel & 250 & 0.0011 \\
Nitrogen & 100 & 0.0019 \\
Samarium & 1.0 & 0.5336 \\
Silicon & 250 & 0.0001 \\
Silver & 25 & 0.0083 \\
Tantalum & 250 & 0.0016 \\
Thorium & 250 & 0.0001 \\
Tin & 250 & 0.0001 \\
Zinc & 250 & 0.0002 \\
\hline Total & 2500 & - \\
\hline & & \\
\hline
\end{tabular}

\subsubsection{Isotopic Analysis}

The supplier shall certify the isotopic compositions of pellets made from each lot of MOX powder. The analyses shall report as a minimum the following isotopes: ${ }^{234} \mathrm{U},{ }^{235} \mathrm{U},{ }^{236} \mathrm{U},{ }^{238} \mathrm{U},{ }^{238} \mathrm{Pu},{ }^{239} \mathrm{Pu}$, ${ }^{240} \mathrm{Pu},{ }^{241} \mathrm{Pu}$, and ${ }^{242} \mathrm{Pu}$.

\subsection{GRINDING}

The sintered pellets shall be dry centerless ground to final dimensions. Immediately after grinding, the pellets must be visibly clean before further handling. These processes shall be described in the approved FITP.

\subsection{WORKMANSHIP}

The surface of finished pellets shall be visibly free from loose MOX powder, oil, or other foreign material. 


\subsection{DIMENSIONS AND FINISH}

The finished pellet surface shall be $1.5 \mu \mathrm{m}$ AA or better. All pellets shall be essentially free from abnormalities and surface imperfections. Surface imperfections are grouped as follows:

1. chipping of the dished and flat ends,

2. chipping of the circumferential surface,

3. pits,

4. inclusions,

5. cracks in pellet surfaces,

6. end-capping and end-flaking,

7. noncleanup, and

8. grinding marks.

The following dimensions for abnormalities and surface imperfections are nominal. Pellets shall be visually inspected and compared to applicable LANL visual standards as described in the FITP.

\subsubsection{Chipping of the Dished and Flat Ends}

Chips spaced closer than $3.0 \mathrm{~mm}$ shall be considered as a single chip.

Chips less than $0.1 \mathrm{~mm}$ deep and chips located wholly within $0.5 \mathrm{~mm}$ of the pellet corner shall be discounted.

The major dimension of any single chip shall not exceed $30 \%$ of the pellet diameter, and the total length of all chips shall not exceed $100 \%$ of the pellet diameter in the major dimension.

\subsubsection{Chipping of the Circumferential Surface}

Chips on the circumferential surface with major dimensions not exceeding $0.5 \mathrm{~mm}$ and chips wholly within $0.5 \mathrm{~mm}$ of the pellet corner shall be discounted. Pellets with chips located on the cylindrical surface are acceptable if the total length of chips is not in excess of $75 \%$ of the pellet diameter.

\subsubsection{Pits}

Pits in any surface with major dimensions not exceeding $0.5 \mathrm{~mm}$ shall be discounted. Pellets with pits shall be acceptable if (1) no pit is larger than $2.5 \mathrm{~mm}$, (2) no more than two pits are larger than $1.0 \mathrm{~mm}$, and (3) no more than 15 pits are larger than $0.5 \mathrm{~mm}$.

\subsubsection{Inclusions in Pellet Surface}

Inclusions with major dimensions not exceeding $0.2 \mathrm{~mm}$ shall be discounted. Pellets with inclusions are acceptable if (1) no inclusion is larger than $0.6 \mathrm{~mm}$ and (2) no more than two inclusions are in the pellet surface. If any inclusions are removed, requirements for chips and pits shall apply.

\subsubsection{Cracks in Pellet Surfaces}

Pellets with circumferential cracks away from pellet ends ( $2 \mathrm{~mm}$ or more away from the edge of the ground surface) are acceptable if the crack length (individual or aggregate) is below $50 \%$ of the pellet circumference.

Cracks on the end face shall not exceed $50 \%$ of the pellet diameter.

Pellets with cracks within $2 \mathrm{~mm}$ from the edge of the ground surface are acceptable if (1) defect length (individual or aggregate) is below $50 \%$ of the pellet circumference and (2) the pellets show adequate resistance to chipping in the defected area. A drop test shall be used to test pellets for acceptability; the test shall be agreed on by the purchaser and the supplier. 


\subsubsection{End-Capping and End-Flaking}

Pellets showing end-capping or end-flaking are not acceptable.

\subsubsection{Noncleanup}

Ground pellets that contain an area of unground surface (noncleanup) shall be acceptable if

1. they represent less than $5 \%$ of the total batch,

2. the noncleanup extends no more than $75 \%$ of the pellet length,

3. at least $10 \%$ of the pellet length at each end of the pellet is ground to the required diameter, and

4. the pellets otherwise meet the specified diametral clearance in the cladding tube.

\subsubsection{Grinding Marks}

Pellets containing visible grinding wheel marks shall be unacceptable, unless said marks do not exceed $0.05 \mathrm{~mm}$ in depth. Pellets with grinding wheel marks that extend more than two revolutions of the pellet circumference are unacceptable.

\subsection{DENSITY}

The sintered pellet density shall be $95 \% \pm 1 \%$ of the theoretical density of a solid solution of the mixed oxides at the target composition. The theoretical density shall be as specified in the relevant purchase order.

At least ten pellets per batch shall be tested for densification in a resintering test. The pellets will be resintered at a temperature of $1750^{\circ} \mathrm{C} \pm 50^{\circ} \mathrm{C}$ for a minimum 24 -h period in a reducing environment consisting of $\mathrm{Ar}-6 \% \mathrm{H}_{2}$. The mean density change shall be less than $1.5 \%$ of theoretical density.

\subsection{PELLET DIMENSIONS}

Pellet dimensions shall comply with the ORNL engineering drawing X2E801214A009, ATR FMDP Experiment-ATR FMDP Fuel Pellet: Fuel Pellet Detail, and the applicable purchase order. ${ }^{2}$ The pellet height shall be $0.400 \pm 0.020 \mathrm{in}$., and the diameter shall be $0.327+0.000 /-0.001 \mathrm{in}$. The pellets shall have a dish and a chamfer at both the top and bottom. The nominal dish dimensions, certified by the punch dimensions and shrinkage calculations, shall include a diameter of $0.230 \pm 0.010$ in. and a depth of $0.008 \pm$ $0.002 \mathrm{in}$., with a nominal radius of curvature of $0.831 \mathrm{in}$. The chamfer shall have a nominal shoulder height (in the axial direction) of $0.008 \pm 0.002$ in. and a width of $0.012 \pm 0.002 \mathrm{in}$., certified by the punch dimensions and shrinkage calculations. A pellet marking system, described in the FITP, shall be used to prevent inadvertent mixing of the fuel types.

\subsection{MICROSTRUCTURE}

\subsubsection{Grain Structure}

A longitudinal cross-section on the diameter of the pellet, prepared and examined in accordance with the procedure described in Appendix A, shall show (1) no visible boundaries of granules persisting from the powder and (2) an average grain size between 5 and $35 \mu \mathrm{m}$. The grain size distribution and pore size distribution are not specified, but shall be measured and reported.

\subsubsection{Homogeneity}

1. For macroscopic quantities of $\sim 0.5$-g mass or larger, the concentration of fissile plutonium shall not deviate from that specified on the drawing or in the purchase agreement. The weight percent 
concentration of fissile plutonium shall be defined as the weight of ${ }^{239} \mathrm{Pu}+{ }^{241} \mathrm{Pu}$ divided by the weight of total uranium plus plutonium metal.

2. The homogeneity of the plutonium content shall be demonstrated through analysis of representative macroscopic samples as defined above. Such representative samples obtained from finished pellets shall be in accordance with the purchase agreement such that the total plutonium content, defined as the weight of plutonium metal divided by the sum of the weights of plutonium and uranium, does not depart from the nominal by more than $\pm 1 \%$ relative.

3. No more than $5 \%$ of the nominal $\mathrm{PuO}_{2}$ content shall be present in $\mathrm{PuO}_{2}$-rich (having a plutonium content greater than $150 \%$ of the nominal bulk composition) particles of diameter greater than $200 \mu \mathrm{m}$. The method of measurement shall be by agreement between the purchaser and supplier. Area percent and volume percent should be considered equivalent if the homogeneity requirements of item 1 are satisfied.

Following the procedure in NE F11-4T, a figure of merit value $(M=0.98)$ for fuel pellet homogeneity may be established.

\section{QUALITY ASSURANCE REQUIREMENTS}

\subsection{GENERAL}

Pellet manufacture, inspection, and documentation shall be in accordance with 10 CFR 830.120, Quality Assurance Requirements, and with the applicable LANL Quality Assurance Program requirements. Additional QA requirements will be specified in the purchase order.

\subsection{ACCESS}

The supplier shall provide reasonable access to the manufacturing facility for the purchaser's representatives to ensure that the provisions of this specification are met.

\subsection{ISOTOPIC COMPOSITION}

The purchaser reserves the right to verify the isotopic composition of samples taken from any pellet batch or powder lot and to reject batches or lots that fail to comply with the composition specified in the purchase order.

\subsection{NUMBER OF TESTS}

Sampling and frequency of testing shall be specified in the FITP and shall be as agreed between the supplier and purchaser.

\subsection{RETESTING}

If any sample or specimen is obviously not representative of the batch or of the lot due to improper preparation or testing, it shall be discarded and replaced by a new sample or specimen. If any of the test results do not meet the specification requirements, retesting shall be performed as mutually agreed between the supplier and purchaser. The suffix " $R$ " shall be used to indicate retest results. 


\subsection{SIGNIFICANCE OF NUMERICAL VALUES}

To determine the compliance with specified limits of property requirements, an observed or calculated value shall be rounded off in accordance with ASTM E29.

\subsection{MATERIALS}

Certified material test reports shall be included in the history file.

\section{PELLET STORAGE, PACKAGING, AND SHIPPING}

Pellet storage, packaging, and shipping shall be subject to appropriate DOE, Department of Transportation, NRC, and other jurisdictional regulations and approvals. Transportation of nuclear materials for the LWR MOX Fuel Irradiation Demonstration Test shall be handled by each DOE shipper site. The project's general plan for the transportation of nuclear materials shall be contained in the Transportation Plan for the FMDP LWR MOX Fuel Irradiation Test Project. ${ }^{3}$

\section{REFERENCES}

1. B. S. Cowell and S. A. Hodge, Fissile Materials Disposition Program Light-Water Reactor MixedOxide Fuel Irradiation Test Project Plan, ORNL/MD/LTR-78, Lockheed Martin Energy Research Corp., Oak Ridge National Laboratory, to be published July 1997.

2. B. S. Cowell, Purchase Order for Low-Enriched Uranium and Mixed-Oxide Fuel Pin Assemblies, ORNL/MD/LTR-77, Lockheed Martin Energy Research Corp., Oak Ridge National Laboratory, to be published June 1997.

3. M. J. Welch, Transportation Plan for the LWR MOX Fuel Irradiation Test Project, ORNL/MD/LTR-87, Lockheed Martin Energy Research Corp., Oak Ridge National Laboratory, to be published September 1997. 


\section{APPENDIX A: \\ EVALUATION OF MICROSTRUCTURE}

\section{A.1 SPECIMEN PREPARATION}

Specimens shall be prepared by mounting a longitudinal section taken on a diameter in a suitable holding medium. The exposed section shall be ground and polished using standard metallographic techniques. Polished sections shall be etched, for example, in a solution of one part concentrated sulfuric acid and nine parts $30 \% \mathrm{H}_{2} \mathrm{O}_{2}$ to reveal the grain structure. The specimens shall be examined as per Sect. 4.10.1 of this specification.

\section{A.2 GRAIN SIZE MEASUREMENT}

The grain size shall be measured by the lineal intercept (Heyn) method according to ASTM E112. The total width of pores intercepted by the test line or lines shall be measured and subtracted from the total length of the test line or lines. Pores lying wholly within individual grains shall be ignored.

\section{A.3 MEASUREMENT LOCATIONS}

Measurements shall be taken as shown in Fig. A.1 at the following five positions on the section:

1. approximately at the center;

2. at two positions along a line through the center normal to the longitudinal axis, not less than one-third of the pellet diameter from the center; and

3. at two positions along the longitudinal axis of the pellet, not less than one-third of the pellet height from the center.

The grain size values measured in these five positions shall be quoted, and the average shall be the average grain size of the pellet.

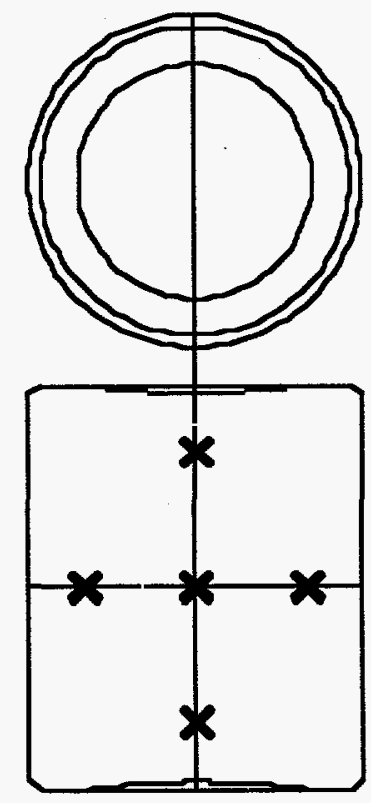

Fig. A.1. Measurement locations for microstructure evaluation. 
ORNL/MD/LTR-75

\section{INTERNAL DISTRIBUTION}

$\begin{aligned} \text { 1. } & \text { B. B. Bevard } \\ 2 . & \text { S. L. Byerly } \\ 3 . & \text { G. L. Copeland } \\ 4 . & \text { B. S. Cowell } \\ 5 . & \text { E. E. Duncan } \\ 6 . & \text { S. E. Fisher } \\ 7 . & \text { E. C. Fox } \\ 8 . & \text { R. G. Gilliland } \\ 9-13 . & \text { S. R. Greene } \\ 14 . & \text { D. W. Heatherly } \\ 15 . & \text { S. A. Hodge } \\ 16 . & \text { S. B. Ludwig } \\ 17 . & \text { G. T. Mays } \\ \text { 18. } & \text { G. E. Michaels } \\ 19 . & \text { W. A. Miller } \\ 20 . & \text { R. N. Morris } \\ 21 . & \text { D. G. O'Connor }\end{aligned}$

\author{
22. L. J. Ott \\ 23. J. V. Pace III \\ 24. R. T. Primm III \\ 25. R. C. Puglisi \\ 26. P. L. Rittenhouse \\ 27. C. C. Southmayd \\ 28. D. J. Spellman \\ 29. J.F. Thomas \\ 30. K. R. Thoms \\ 31. M. J. Welch \\ 32. D. L. Williams, Jr. \\ 33. Central Research Library \\ 34. Y-12 Technical Library \\ 35. ORNL Patent Section \\ 36-37. ORNL Laboratory Records (OSTI) \\ 38. ORNL Laboratory Records-RC
}

\section{EXTERNAL DISTRIBUTION}

39. D. Alberstein, Los Alamos National Laboratory, P.O. Box 1663, MS-K575, Los Alamos, NM 87545 .

40. J. Baker, U.S. Department of Energy, MD-3, 1000 Independence Avenue SW, Washington, DC 20585.

41. J. J. Buksa, Los Alamos National Laboratory, P.O. Box 1663, MS-K551, Los Alamos, NM 87545.

42. H. R. Canter, U.S. Department of Energy, MD-3, 1000 Independence Avenue SW, Washington, DC 20585.

43-45. K. Chidester, Los Alamos National Laboratory, P.O. Box 1663, MS-E502, Los Alamos, NM 87545 .

46. H. E. Clark, U.S. Department of Energy, Oak Ridge Operations, P.O. Box 2008, Oak Ridge, TN 37831-6269.

47. C. Cliche, Westinghouse Savannah River Corp., Building 704-16F, Room 10, Aiken, SC 29808.

48. D. Cox, Atomic Energy of Canada Limited, Chalk River Laboratories, Chalk River, Ontario, Canada KOJ $1 \mathrm{JO}$.

49. J. Gingold, S. M. Stoller Corp., 485 Washington Avenue, Pleasantville, NY 10570.

50. D. Peko, U.S. Department of Energy, 1000 Independence Avenue SW, Forrestal Building 6G-050, MS MD-3, Washington, DC 20585.

51. P. T. Rhoads, U.S. Department of Energy, MD-3, 1000 Independence Avenue SW, Forrestal Building 6G-050, Washington, DC 20585.

52-55. J. M. Ryskamp, Idaho National Engineering and Environmental Laboratory, MS 3885, P.O. Box 1625, Idaho Falls, ID 83415-3885.

56. R. H. Steele, MPR Associates Inc., 320 King Street, Alexandria, VA 22314-3238.

57. M. L. Thompson, 44850 Parkmeadow, Fremont, CA 94539. 